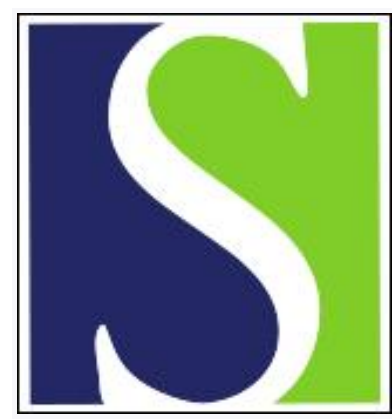

Scand J Work Environ Health 1986;12(5):486-493

https://doi.org/10.5271/sjweh.2109

Issue date: Oct 1986

Estimating the relationship between exposure to tar volatiles and the incidence of bladder cancer in aluminum smelter workers.

by Armstrong BG, Tremblay CG, Cyr D, Theriault GP

This article in PubMed: www.ncbi.nlm.nih.gov/pubmed/3787220

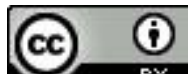




\title{
Estimating the relationship between exposure to tar volatiles and the incidence of bladder cancer in aluminum smelter workers
}

\author{
by Ben G Armstrong, PhD, Claude G Tremblay, MSc, Diane Cyr, MA, \\ Gilles P Thériault, MD, DrPH, CSPQ ${ }^{1}$
}

\begin{abstract}
ARMSTRONG BG, TREMBLAY CG, CYR D, THÉRIAULT GP. Estimating the relationship between exposure to tar volatiles and the incidence of bladder cancer in aluminum smelter workers. Scand J Work Environ Health 12 (1986) 486-493. A previously reported case-referent study of 85 incident cases of bladder cancer among aluminum smelter workers and 255 matched referents revealed an excess risk among workers exposed to coal-tar pitch volatiles. For the study reported in the present investigation these data have been augmented by estimates of past workplace exposure to total tar (benzene-soluble matter) and to benzoa-pyrene $(\mathrm{BaP})$. From these new data, exposure-response relationships have been estimated by maximum likelihood. A linear relationship between cumulative exposure and relative risk and a minimum latency period of ten years were assumed on a priori grounds and found compatible with the data. Under these assumptions, relative risk increased for each year of exposure to benzene-soluble matter at a concentration of $1 \mathrm{mg} / \mathrm{m}^{3}$ by $13 \%$, the $95 \%$ confidence interval being $5-31$. The corresponding figure for BaP (as $\mu \mathrm{g} / \mathrm{m}^{3} \cdot$ year) was $2.3 \%$. On the basis of these estimates, 40 years of exposure to benzene-soluble matter at the current exposure limit of $0.2 \mathrm{mg} / \mathrm{m}^{3}$ would lead to a relative risk of 2.4 . There was suggestive but not conclusive evidence that relative risks due to exposure to tar volatiles and to cigarette smoke combined multiplicatively.
\end{abstract}

Key terms: aluminum smelter, benzene-soluble matter, benzo-a-pyrene, coal-tar pitch, exposure-response, relative risk models.

\begin{abstract}
A case-referent study of 85 incident cases of bladder cancer among aluminum smelter workers was carried out in 1981. The purpose of this study was to identify factors which would explain the excess incidence of bladder cancer found previously among workers at this smelter (9). Results from this study, published in 1984 (10), showed a clear excess risk among Soderberg potroom workers, and the risk was related to duration of employment in this area. The excess was thought most likely to be due to exposure to coal-tar pitch volatiles, given off from the anodes in the Soderberg electrolytic reduction process.
\end{abstract}

Data from this study have subsequently been augmented by quantitative estimates of historical workplace exposure to all benzene-soluble material (BSM), an indicator of overall exposure to tar volatiles, and to benzo-a-pyrene (BaP), as an indicator of polycyclic aromatic hydrocarbons (PAH). These assessments of exposure have been used to estimate exposure-response relationships, which we present in the following report.

\footnotetext{
1 School of Occupational Health, McGill University, Montreal, Quebec, Canada H3A 1A3.
}

Reprint requests to: Dr BG Armstrong, School of Occupational Health, McGill University, 1130 Pine Avenue West, Montreal, Quebec, Canada H3A 1 A3.

\section{Material and methods}

\section{Study design}

Full details of the study design are given in the report by Thériault et al (10). In summary, 85 cases of bladder cancer diagnosed from 1970-1979 in current or former male workers from five aluminum smelters in the province of Quebec were ascertained from the Quebec tumor register and hospital records. Three controls per case were randomly sampled from men who had been employed for at least one year at the same smelter as the case and who had survived without bladder cancer beyond the age of diagnosis of the case, after matching by five-year strata of date of birth, date of starting work at the smelter, and duration of employment at the smelter at the time of diagnosis of the case. Occupational histories of the subjects were obtained from the plants, and smoking histories were sought.

Descriptive statistics of the cases and referents are shown in table 1. Smoking habit data are different from that given in reference 10 , since further efforts were made to identify the smoking habits of men for whom the information had been previously unavailable.

\section{Estimating exposure}

Aluminum is smelted through the reduction of alumina in electrolytic cells called pots. There are basically two types of processes, the Soderberg (until recently accounting for most production in these smelters) and 
the prebake. Exposure to hydrocarbons is caused by the emission, especially from Soderberg anodes, of coal-tar pitch volatiles.

The time-weighted average (TWA) concentrations of BSM were estimated for each of 297 groups of occupations by industrial hygienists working at the plant. The estimates were based on routine air measurements going back to the $1950 \mathrm{~s}$. Where concentrations had changed over time, separate estimates were made for each quinquennium. All environmental sampling was for particulate solids; therefore gaseous hydrocarbons were excluded. Mostly personal sampling has been carried out since 1972, and stationary sampling before then. Estimates of TWA concentrations based on the stationary samples accounted for the differences observed between these and the personal samples in the overlap period. For time periods for which no measurements relating to a job were made, estimates were extrapolated from those for later time periods and other jobs, changes in anode material, operating conditions, and building ventilation being taken into account.

As BaP measurements were available only from 1976 on, the estimates of $\mathrm{BaP}$ were made indirectly. First, an estimate of the proportion of $\mathrm{BaP}$ exposure in BSM (BaP:BSM ratio) was obtained from $\mathrm{BaP}$ and $\mathrm{BSM}$ measurements made between 1976 and 1983 for each of 19 broad occupational groups. Second, these proportions were used to convert the BSM concentrations, including those relating to the period before 1976, to $\mathrm{BaP}$ concentrations. This procedure implicitly assumes that the BaP:BSM ratio did not change over the time of operation of the smelter. The assumption could not be tested empirically, but, since the processes did not change qualitatively, it is likely that the BaP:BSM ratios were fairly constant.

No estimates of other fractions of tar volatiles or of other specific components of PAH were available.

Estimates of the BSM concentration and the proportion of BaP in BSM for the main occupations are shown in table 2. Jobs in the Soderberg potroom entailed the highest exposures to BSM, certain jobs in potlining (which involved working in the Soderberg potroom) and in the carbon plant (where the anode is prepared) also involving substantial exposure. BSM exposure in the prebake potroom was much lower than in those jobs already mentioned. Jobs in the smelter for which exposure to tar volatiles was essentially zero (notably maintenance, casting, and work in the chemical plant, where the bauxite ore was processed) accounted for a substantial proportion (about $40 \%$ ) of the workforce.

The BaP:BSM ratio was estimated to be around $10 \mu \mathrm{g}: 1 \mathrm{mg}$ in the Soderberg potroom (and thus for some jobs in potlining also). This figure is close to the ratio of $13 \mu \mathrm{g}: 1 \mathrm{mg}$ found in Swedish Soderberg potrooms (7). The ratio was about one-tenth of the Soderberg value in the prebake potroom and in the carbon plant. Thus for BaP exposure even more than for BSM exposure, the Soderberg potroom was the predominant source.

In areas in which exposures were originally high, successive control measures have steadily decreased exposures to 1979 , and further since then. Only from 1975 has the wearing of masks (type 3M-8706) been required in the potrooms. Thus mask use is unlikely to have influenced tar exposure importantly over the period relevant for this study.

Cumulative exposure to BSM (in milligrams/cubic meter of air $\times$ years of exposure) and to $\mathrm{BaP}$ (in micrograms/cubic meter of air $\times$ years of exposure) was calculated for each worker as the sum of the products of concentration and duration on each job. Cumulation was to the date of diagnosis of each case (or matched case for referents.) To reflect a possible minimum latency period before which exposure could have led to a diagnosed cancer, cumulative exposure was also calculated discounting the 10 years immediately preceding that date.

\section{Statistical methods}

The relationship between cumulative exposure and the relative risk of bladder cancer was investigated with

Table 1. Description of the cases and referents.

\begin{tabular}{|c|c|c|c|c|c|c|c|c|}
\hline \multirow{2}{*}{ Characteristic } & \multicolumn{4}{|c|}{ Cases $(\mathrm{N}=85)$} & \multicolumn{4}{|c|}{ Referents $(\mathrm{N}=255$ ) } \\
\hline & Mean & SD & $N$ & $\%$ & Mean & SD & $\mathbf{N}$ & $\%$ \\
\hline Age at diagnosis (years) ${ }^{a}$ & 61.7 & 9.4 & . & . & . & . & . & . \\
\hline Age at hire at smelter (years) ${ }^{a}$ & 28.2 & 7.3 & . & . & 28.9 & 7.3 & . & . \\
\hline $\begin{array}{l}\text { Length of employment at smelter } \\
\text { (years) }^{\mathrm{a}}\end{array}$ & 23.9 & 9.8 & . & . & 24.1 & 10.6 & . & . \\
\hline \multicolumn{9}{|l|}{ Cumulative exposure } \\
\hline $\begin{array}{l}\text { Benzene-soluble matter } \\
\text { (mg/m } / \mathrm{m}^{3} \cdot \text { years) } \\
\text { Benzo-a-pyrene }\left(\mathrm{mg} / \mathrm{m}^{3} \cdot \text { years) }\right.\end{array}$ & $\begin{array}{r}15.3 \\
136.6\end{array}$ & $\begin{array}{r}15.5 \\
169.9\end{array}$ & . & $\dot{.}$ & $\begin{array}{r}8.1 \\
58.8\end{array}$ & $\begin{array}{r}10.6 \\
103.7\end{array}$ & $\dot{.}$ & $\dot{.}$ \\
\hline \multicolumn{9}{|l|}{ Smoking } \\
\hline $\begin{array}{l}\text { Ever } \\
\text { Never } \\
\text { Unknown }\end{array}$ & $\dot{.}$ & $\dot{.}$ & $\begin{array}{r}79 \\
6 \\
-\end{array}$ & $\begin{array}{r}92.9 \\
7.1 \\
0.0\end{array}$ & $\dot{.}$ & $\dot{.}$ & $\begin{array}{r}197 \\
46 \\
12\end{array}$ & $\begin{array}{r}77.3 \\
18.0 \\
4.7\end{array}$ \\
\hline
\end{tabular}

a Matching variable. 
Table 2. Estimated time-weighted average concentrations of benzene-soluble matter (BSM) and the benzo-a-pyrene (BaP): BSM ratio determined for selected occupations.

\begin{tabular}{|c|c|c|c|c|c|c|c|}
\hline \multirow{2}{*}{ Plant area } & \multicolumn{6}{|c|}{ BSM concentration $\left(\mathrm{mg} / \mathrm{m}^{3}\right)$} & \multirow{2}{*}{$\begin{array}{c}\mathrm{BaP}: \mathrm{BSM} \\
(\mu \mathrm{g}: \mathrm{mg})\end{array}$} \\
\hline & $1930-1954$ & $1955-1959$ & $1960-1964$ & $1965-1969$ & $1970-1974$ & $1975-1979$ & \\
\hline \multicolumn{8}{|l|}{ Soderberg } \\
\hline $\begin{array}{l}\text { Potman } \\
\text { Channel mounter } \\
\text { Rod raiser } \\
\text { Stud puller } \\
\text { Laborer }\end{array}$ & $\begin{array}{l}1.6 \\
2.0 \\
3.5 \\
2.5 \\
0.50\end{array}$ & $\begin{array}{l}1.0 \\
2.0 \\
3.5 \\
2.5 \\
0.39\end{array}$ & $\begin{array}{l}1.0 \\
1.8 \\
2.0 \\
2.1 \\
0.39\end{array}$ & $\begin{array}{l}0.8 \\
1.4 \\
1.4 \\
2.1 \\
0.30\end{array}$ & $\begin{array}{l}0.8 \\
1.2 \\
0.9 \\
0.38 \\
0.30\end{array}$ & $\begin{array}{l}0.4 \\
0.54 \\
0.8 \\
0.38 \\
0.15\end{array}$ & $\begin{array}{r}8.8 \\
10.8 \\
10.1 \\
17.5 \\
13.0\end{array}$ \\
\hline \multicolumn{8}{|l|}{ Prebake } \\
\hline $\begin{array}{l}\text { Potman } \\
\text { Alumina unioader } \\
\text { Laborer }\end{array}$ & $\begin{array}{l}0.10 \\
0.05 \\
0.10\end{array}$ & $\begin{array}{l}0.10 \\
0.05 \\
0.10\end{array}$ & $\begin{array}{l}0.10 \\
0.05 \\
0.08\end{array}$ & $\begin{array}{l}0.10 \\
0.05 \\
0.08\end{array}$ & $\begin{array}{l}0.10 \\
0.05 \\
0.06\end{array}$ & $\begin{array}{l}0.10 \\
0.05 \\
0.06\end{array}$ & $\begin{array}{l}0.0 \\
1.2 \\
0.4\end{array}$ \\
\hline \multicolumn{8}{|l|}{ Potlining area } \\
\hline $\begin{array}{l}\text { Pot replacer } \\
\text { Pot baker } \\
\text { Laborer }\end{array}$ & $\begin{array}{l}2.5 \\
0.54 \\
0.72\end{array}$ & $\begin{array}{l}1.5 \\
0.48 \\
0.57\end{array}$ & $\begin{array}{l}0.61 \\
0.48 \\
0.57\end{array}$ & $\begin{array}{l}0.47 \\
0.43 \\
0.44\end{array}$ & $\begin{array}{l}0.47 \\
0.43 \\
0.22\end{array}$ & $\begin{array}{l}0.40 \\
0.43 \\
0.17\end{array}$ & $\begin{array}{r}14.1 \\
1.2 \\
14.1\end{array}$ \\
\hline \multicolumn{8}{|l|}{ Carbon plant } \\
\hline $\begin{array}{l}\text { Conveyer operator } \\
\text { Crusher operator } \\
\text { Laborer }\end{array}$ & $\begin{array}{l}0.71 \\
1.2 \\
0.72\end{array}$ & $\begin{array}{l}0.63 \\
1.0 \\
0.57\end{array}$ & $\begin{array}{l}0.63 \\
1.0 \\
0.57\end{array}$ & $\begin{array}{l}0.56 \\
0.92 \\
0.44\end{array}$ & $\begin{array}{l}0.31 \\
0.46 \\
0.22\end{array}$ & $\begin{array}{l}0.31 \\
0.39 \\
0.17\end{array}$ & $\begin{array}{l}0.3 \\
1.4 \\
1.2\end{array}$ \\
\hline Casting area & 0.0 & 0.0 & 0.0 & 0.0 & 0.0 & 0.0 & 0.0 \\
\hline Chemical plant & 0.0 & 0.0 & 0.0 & 0.0 & 0.0 & 0.0 & 0.0 \\
\hline
\end{tabular}

Table 3. Estimates of the exposure-response models. $(95 \% \mathrm{Cl}=$ confidence interval, $\mathrm{df}=\mathrm{degree}$ of freedom)

\begin{tabular}{|c|c|c|c|}
\hline \multirow{2}{*}{ Exposure index } & \multicolumn{2}{|c|}{$\begin{array}{l}\text { Relative risk } \\
\text { slope parameter }\end{array}$} & \multirow{2}{*}{$\begin{array}{l}\text { Likelihood } \\
\text { ratio chi-squared } \\
\text { against } b=0(1 \mathrm{df})\end{array}$} \\
\hline & $b^{a}$ & $95 \% \mathrm{Cl}$ & \\
\hline Time in potroom (years) & 0.213 & $0.08-0.47$ & 25.4 \\
\hline Benzene-soluble matter $\left(\mathrm{mg} / \mathrm{m}^{3}\right.$-years) & 0.131 & $0.05-0.31$ & 22.3 \\
\hline $\begin{array}{l}\text { Benzene-soluble matter }\left(\mathrm{mg} / \mathrm{m}^{3} \cdot \text { years }\right) \\
\text { with } 10 \text { years' latency }\end{array}$ & 0.177 & $0.07-0.41$ & 25.3 \\
\hline Benzo-a-pyrene $\left(\mu \mathrm{g} / \mathrm{m}^{3}\right.$-years $)$ & 0.0182 & $0.007-0.042$ & 27.4 \\
\hline $\begin{array}{l}\text { Benzo-a-pyrene }\left(\mu \mathrm{g} / \mathrm{m}^{3} \text {-years }\right) \\
\text { with } 10 \text { years' latency }\end{array}$ & 0.023 & $0.009-0.052$ & 29.1 \\
\hline
\end{tabular}

a Assuming linear model $R=1+b x ; b$ represents estimated increment in relative risk per unit of exposure.

the use of conditional binary regression techniques for matched case-referent data (11), equivalent to Cox's proportional hazards model for survival data. The linear relative risk model was adopted for most of the analyses. This model assumes that relative risk $R$ (more precisely odds ratio) is related to exposure $x$ through the equation $R=1+b x$. The slope parameter $b$ is estimated from the data and may be interpreted as the increase in relative risk per unit of exposure. In addition to exposure being considered a continuous variable in the preceding model, the subjects were divided into groups according to exposure, and the risk for each group was estimated relative to the lowest, also with the use of a matched analysis.

The null hypotheses of no association between exposure and relative risk $(b=0)$ was tested with the likelihood ratio (LR) chi-squared test, and the $95 \%$ confidence intervals for $b$ were also calculated by the LR method, which does not require that the estimate of $b$ be normally distributed. The goodness of fit of models with the same number of parameters were com- pared through their LR statistics, a higher LR indicating a better fit (12). Somewhat informally, we refer these differences in LR statistics to the chi-squared distribution on one degree of freedom (df), following the argument that each model may be considered to be a special case of a more general "mixture" model of the two combined (11).

The relationship between cigarette smoking $\left(x_{1}\right)$ and exposure to tar volatiles $\left(x_{2}\right)$ was investigated with the use of linear multiplicative $\left[R=\left(1+b_{1} x_{1}\right)\left(1+b_{2} x_{2}\right)\right]$ and additive $\left(R=1+b_{1} x_{1}+b_{2} x_{2}\right)$ models, as described by Thomas (11). Since quantitative information on smoking was unavailable for many cases and referents, a simple indicator variable taking the value 1 for ever having been a cigarette smoker and 0 for never having been a cigarette smoker was used to represent smoking in the models used. The 12 referents with unknown smoking habits were excluded from these analyses. As there remained at least one referent for each case, matched analyses could still be carried out. 

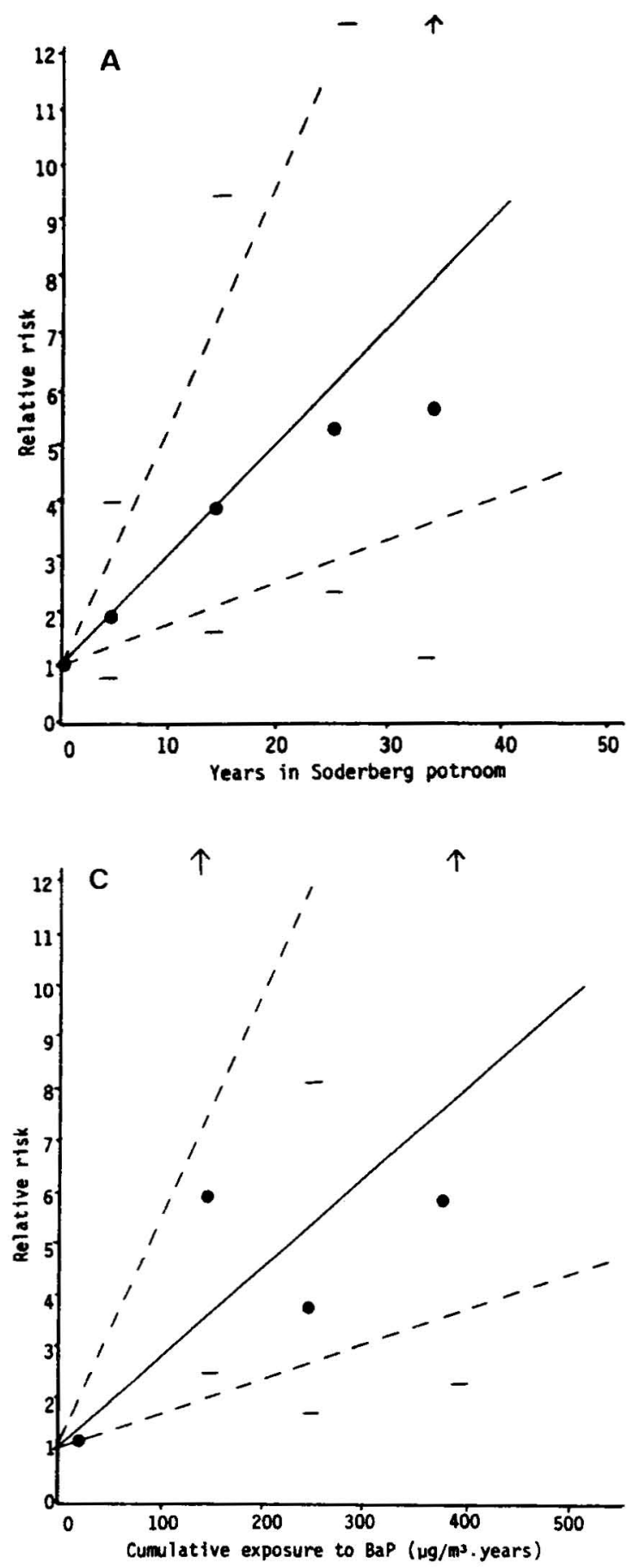

\section{Results}

Estimates of slope $b$ of the exposure-response relationships are tabulated in table 3 and shown in graphs in figure 1 for the following three indices: years spent in the potroom, cumulative exposure to BSM, and cumulative exposure to BaP. All these relationships were highly statistically significant $(p<0.001)$. Estimates of relative risk by exposure group (according to each

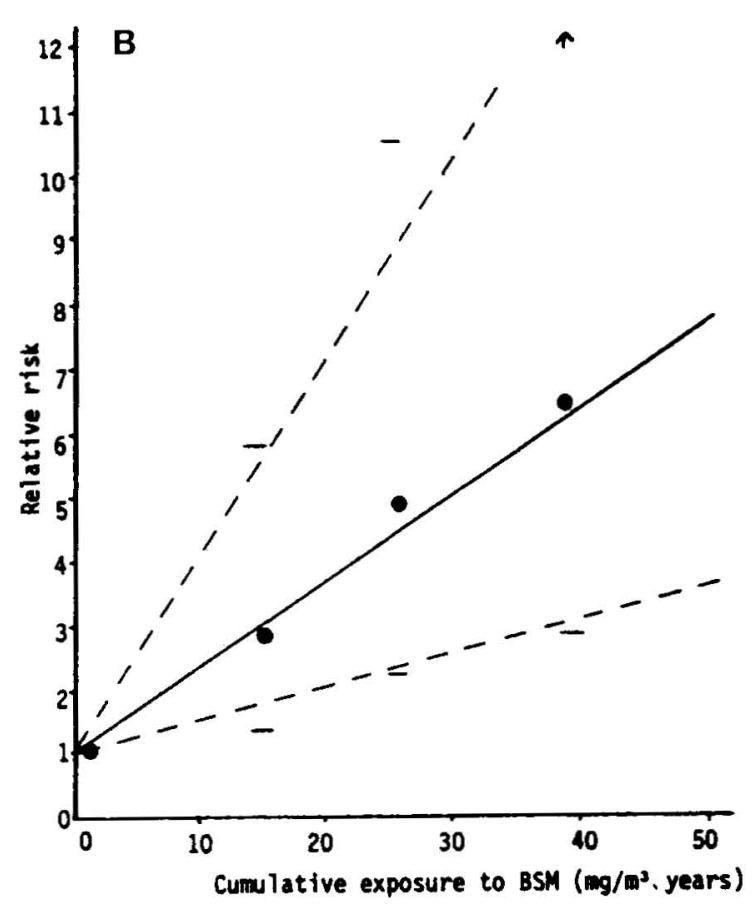

Figure 1. Relative risk by years in the Soderberg potroom (A), by cumulative exposure to benzene-soluble matter (BSM)(B), and cumulative exposure to benzo-a-pyrene (BaP) (C). (Solid line = estimated linear model, filled circles and short horizontal lines = estimated relative risks and the $95 \%$ confidence intervals, respectively, for the exposure groups)

of the three indices) are shown in table 4 and indicated as filled circles on the figures. The three exposure indices used are strongly correlated [years in potroom with BSM, correlation coefficient $(\mathrm{r}) 0.81$; years in potroom with $\mathrm{BaP}, \mathrm{r}=0.77$; $\mathrm{BSM}$ with $\mathrm{BaP}, \mathrm{r}=0.93$ ], and this correlation is reflected in the similar fit, represented by the likelihood ratio, of the models based on each index. Also shown in table 3, are models based on exposure to $\mathrm{BSM}$ and $\mathrm{BaP}$ cumulated to 10 years 
before the diagnosis of the case (" 10 years latency"). Estimates of the relative risk increment $b$ for these indices are slightly higher than those based on the overall cumulative exposures, and the likelihood ratio against the null hypothesis is slightly larger.

Relative risk predicted by the models to follow from a given exposure may be calculated by the substitution of appropriate values of $b$ and $x$ in the equation $R=1+b x$; for example, a cumulative exposure of $\overline{1} 00 \mu \mathrm{g} / \mathrm{m}^{3} \cdot$ years of $\mathrm{BaP}$ is predicted to give rise (after 10 years of latency) to a relative risk of $1+0.023 \times$ $100=3.3$, according to the " 10 -year latency" model.

Smoking was not importantly related to coal-tar pitch exposure among the referents (eg, $85 \%$ of the referents who had ever worked in the potroom were smokers, compared with $80 \%$ of other referents), so that we may assume that this was approximately the case in the smelter population as a whole. Thus

Table 4. Estimates of relative risk by exposure group. ${ }^{a}$

\begin{tabular}{|c|c|c|c|}
\hline Exposure index ${ }^{a}$ & $\begin{array}{l}\text { Relative } \\
\text { risk }\end{array}$ & $\begin{array}{c}95 \% \\
\text { confidence } \\
\text { interval }\end{array}$ & $\begin{array}{l}\text { Likelihood ratio } \\
\text { chi-squared } \\
\text { against } b=0^{b}\end{array}$ \\
\hline \multicolumn{4}{|l|}{$\begin{array}{l}\text { Time in potroom } \\
\text { (years) }\end{array}$} \\
\hline $\begin{array}{l}0-(40) \\
1-(12) \\
10-(12) \\
20-(18) \\
30-(3)\end{array}$ & $\begin{array}{l}1.0 \\
1.82 \\
3.92 \\
5.29 \\
5.75\end{array}$ & $\begin{array}{l}0.8-4.0 \\
1.6-9.6 \\
2.3-12.2 \\
1.1-31.5\end{array}$ & $21.4(4)$ \\
\hline \multicolumn{4}{|l|}{$\begin{array}{l}\text { Benzene-soluble } \\
\text { matter } \\
\left(\mathrm{mg} / \mathrm{m}^{3} \cdot \text { years }\right)\end{array}$} \\
\hline $\begin{array}{r}0-(39) \\
10-(14) \\
20-(15) \\
30-(17)\end{array}$ & $\begin{array}{l}1.0 \\
2.75 \\
4.81 \\
6.30\end{array}$ & $\begin{array}{l}1.3-5.7 \\
2.2-10.5 \\
2.8-14.1\end{array}$ & 26.1 (3) \\
\hline \multicolumn{4}{|l|}{$\begin{array}{l}\text { Benzo-a-pyrene } \\
\left(\mu \mathrm{g} / \mathrm{m}^{3} \cdot \text { years }\right)\end{array}$} \\
\hline $\begin{array}{l}0-(45) \\
100-(17) \\
200-(13) \\
300-(10)\end{array}$ & $\begin{array}{l}1.0 \\
5.86 \\
3.78 \\
5.89\end{array}$ & $\begin{array}{l}2.4-14.3 \\
1.7-8.4 \\
2.2-15.9\end{array}$ & 27.1 (3) \\
\hline
\end{tabular}

a Estimates of relative risk are relative to the lowest exposure group. Numbers of cases in each group are shown in parentheses.

b Degrees of freedom in parentheses. smoking did not confound the relationship between coal-tar pitch volatiles and bladder cancer. The separate and combined effect of exposure to tar volatiles and cigarette smoking was estimated with the linear model for exposure to $\mathrm{BSM}$ and $\mathrm{BaP}$, and under the assumptions (i) that the two factors act multiplicatively on relative risk and (ii) that they act additively. These estimates are shown in table 5. All models show a relative risk for smoking of between three and four. Differences in likelihood between the models indicate an improvement in fit of the multiplicative models over the additive models $(0.05<\mathrm{p}<0.10$ for both BSM and $\mathrm{BaP}$ ), and for $\mathrm{BaP}$ models over BSM models $(0.01<\mathrm{p}<0.05$ for both the multiplicative and additive models).

\section{Discussion}

The existence of an association between exposure to coal-tar pitch volatiles in Soderberg potrooms and excess risk of bladder cancer is already well established $(3,4,10)$. We have attempted in this study to quanti$f y$ this relationship, in the sense of estimating the risk which follows from a given quantity of exposure. Our results are likely to be of interest primarily in discussions of hygienic limits. In this context it is important to be aware of the uncertainties and limitations of the estimates presented, and we have concentrated our discussion on these.

\section{Indices of exposure}

As indices of exposure we used total years spent in the potroom, and cumulative exposure to BSM and BaP, the only two components of tar to have been measured. Although years spent in the potroom is as effective a predictor of observed bladder cancers as the BSM or $\mathrm{BaP}$ indices (judged by likelihood ratio), it is unlikely to be useful for predicting risk in the future or in other smelters, since, where environmental conditions differ, risk per year exposed is unlikely to be the same.

BSM is an estimate essentially of all tar exposure. $\mathrm{BaP}$ was used in addition to BSM not because it was thought that $\mathrm{BaP}$ itself was likely to be the actual

Table 5. Relationship between exposure to tar volatiles, smoking, and bladder cancer risk.

\begin{tabular}{|c|c|c|c|c|}
\hline \multirow[b]{2}{*}{ Exposure } & \multirow[b]{2}{*}{ Model } & \multicolumn{2}{|c|}{ Parameter estimates } & \multirow{2}{*}{$\begin{array}{l}\text { Likelihood ratio chi-squarec } \\
\text { against } b_{1}=b_{2}=0\end{array}$} \\
\hline & & $\begin{array}{c}\text { Smoking } \\
b_{1}\end{array}$ & $\begin{array}{c}\text { Tar } \\
b_{2}\end{array}$ & \\
\hline \multirow[t]{2}{*}{ Benzene-soluble matter } & $\begin{array}{l}\text { Linear-multiplicative } \\
\left(1+b_{1} x_{1}\right)\left(1+b_{2} x_{2}\right)\end{array}$ & 2.15 & 0.139 & 29.8 \\
\hline & $\begin{array}{l}\text { Linear-additive } \\
\left(1+b_{1} x_{1}+b_{2} x_{2}\right)\end{array}$ & 2.59 & 0.36 & 26.6 \\
\hline \multirow[t]{2}{*}{ Benzo-a-pyrene } & $\begin{array}{l}\text { Linear-multiplicative } \\
\left(1+b_{1} x_{1}\right)\left(1+b_{2} x_{2}\right)\end{array}$ & 2.12 & 0.018 & 34.9 \\
\hline & $\begin{array}{l}\text { Linear-additive } \\
\left(1+b_{1} x_{1}+b_{2} x_{2}\right)\end{array}$ & 2.01 & 0.044 & 31.7 \\
\hline
\end{tabular}


causal agent, but in the hope that it might be better correlated to the causal agent(s) than BSM overall. In particular, $\mathrm{BaP}$ is often taken as an indicator of total PAH. More than 30 different PAH have been identified in the work environment in aluminum smelters (2), many of them known to be carcinogenic in animals (6). However, the most plausible agents for bladder carcinogenesis known to be present in tar volatiles appear not to be the PAH but the aromatic amines (in particular 2-naphthylamine), which have been associated with bladder cancer in animal and human studies (5). The relation of concentrations of aromatic amines to BSM and BaP is not known.

To the extent to which other environments have a ratio of the actual causative agent to BSM or to $\mathrm{BaP}$ which is similar to that in the aluminum smelters in this study, the estimates of risk per unit of BSM or BaP will be applicable. Thus we are the most confident in generalizing these results to other smelters using the Soderberg process, somewhat less so to smelters using the prebake process, and less still to environments contaminated with coal-tar pitch volatiles from other sources (eg, coke ovens). To extrapolate the results to completely different mixtures of hydrocarbons (eg, tobacco smoke) would not be sensible.

Fitting a model with both BaP and BSM gives a likelihood ratio of 27.6 (compare 22.3 for BSM alone), giving a formal likelihood ratio test for BaP accounting for BSM of 5.3 on $1 \mathrm{df}(\mathrm{p}<0.02)$. Thus there is some empirical evidence in these data that $\mathrm{BaP}$ is a better indicator of bladder cancer risk than BSM, but this evidence is not strong enough to be conclusive.

\section{Comparisons with other studies}

There are few studies with which we can compare our results. We know of no other ones investigating biadder cancer incidence among aluminum smelters. There have been mortality studies, but none have quantitative estimates of exposure in terms of concentration. Results from a cohort mortality study of workers in the main smelters included in this case-referent study (4) showed an increase in relative mortality per unit of exposure for bladder cancer compatible with the increase in relative incidence found in this study. However, this confirmatory evidence is limited, since (i) the total number of deaths due to bladder cancer was only 13 (so the sampling uncertainty in risk estimates was high) and (ii) exposure estimates were essentially the same as those used in this study. However there was little overlap between the deaths from the cohort and the cases from this case-referent study, so that to this extent the information is complementary.

\section{Uncertainties in estimating exposures}

In most if not all epidemiologic studies from which quantitative exposure-response relationships are estimated, the assessment of exposure is subject to con- siderable uncertainty. The estimates of exposure used for this study are based on a large number of environmental measurements and represent the result of careful work of experienced hygienists working at the largest smelter in the study (accounting for 73 of the 85 cases). The estimates must nevertheless be subject to some doubt, especially the early period. Estimates of air concentrations that are consistently too low or too high would bias estimates of the slope of the exposureresponse relationship up or down, respectively. Less obviously, random error in exposure estimates (equally often too high as too low) would bias the exposureresponse slope towards zero (1). Currently there is no satisfactory way to estimate the extent of this bias without knowledge of the distribution of the random error, which is unavailable. We are currently developing statistical methods which do not require this information, results from which will be published separately.

As a preliminary exercise prior to this study, exposure-response relationships based on much cruder estimates of exposure were investigated. A comparison of these earlier results with those obtained from the more-detailed estimates of the present study highlights some of the problems related to exposure estimation. The preliminary analysis used estimates of cumulative exposure to BSM and $\mathrm{BaP}$ based on dividing jobs into five broad exposure categories assuming no change in exposure over time and assigning a representative exposure to each category. Results from this analysis are summarized in table 6 . Although the crude and detailed exposure estimates were highly correlated $(r=0.82$ for $\mathrm{BaP}$ and for BSM), the cruder estimates surprisingly achieved a significantly higher LR against the null hypothesis, the indication being that they might better reflect the true causal agent(s).

The cruder estimate of BSM gave a considerably higher relative risk increment parameter $b$. Although this result does not imply that the cruder estimates were superior to the more detailed ones, it does when considered together with the higher LR, for the cruder measures suggest caution in predicting risk from mod-

Table 6. A comparison between models based on crude and detailed exposure estimates. (BSM = benzene-soluble matter, $\mathrm{BaB}=$ benzo-a-pyrene, $95 \% \mathrm{Cl}=95 \%$ confidence interval, $\mathrm{df}=$ degree of freedom)

\begin{tabular}{lccc}
\hline $\begin{array}{l}\text { Exposure } \\
\text { index }\end{array}$ & $\begin{array}{c}\text { Relative risk } \\
\text { slope } \\
\text { parameter b }\end{array}$ & $95 \% \mathrm{Cl}$ & $\begin{array}{c}\text { Likelihood ratio } \\
\text { chi-squared } \\
\text { against } \\
\mathrm{b}=0(1 \mathrm{df})\end{array}$ \\
\hline $\begin{array}{l}\mathrm{BSM} \\
\text { (detailed) }\end{array}$ & 0.131 & $0.05-0.31$ & 22.3 \\
$\begin{array}{l}\mathrm{BSM} \\
\text { (crude) }\end{array}$ & 0.37 & $0.13-1.1$ & 31.4 \\
$\begin{array}{l}\text { BaP } \\
\text { (detailed) }\end{array}$ & 0.0182 & $0.007-0.042$ & 24.7 \\
$\begin{array}{l}\text { BaP } \\
\text { (crude) }\end{array}$ & 0.0220 & $0.009-0.058$ & 32.5 \\
\hline
\end{tabular}


els for BSM. The difference between estimates of $b$ for BaP exposure according to the two exposure estimates is much smaller, and for this reason we are somewhat more confident in predicting risk from $\mathrm{BaP}$ exposure.

We are further investigating possible reasons for the greater predictive value of the cruder estimates, so far without discovering any clear pattern. Few, if any, similar studies have made more than one estimate of exposure, and it may be that this exercise simply serves to emphasize that such estimation is generally a highly uncertain procedure.

\section{Implications of study design}

The estimation of relative risk models from casereferent studies is known to be valid and has been used in other occupational contexts, for example, for asbestos exposure and lung cancer risk (11). The present study employed matching on duration of employment at a smelter in addition to the standard matching factors of date of birth, etc. Such matching is desirable to avoid confounding bias if duration of employment is a marker for risk other than through exposure to tar volatiles, but may constitute a form of overmaiching (inappropriately diminishing potential differences in exposure between cases and referents) if not. Such overmatching would not introduce bias into estimates of exposure-response relationships if exposure were measured without error, although it would reduce precision (increase the width of the confidence intervals) compared to designs unmatched for duration of service. However, the biasing effects of random measurement error which were mentioned are likely to be more pronounced in the design matched for duration of service, since variation in true exposure among men with the same duration of exposure is more limited (1). In this study there was a great heterogeneity of exposure between jobs so that correlations between overall length of service and cumulative exposure to BSM $(r=0.29)$ and $\mathrm{BaP}(r=0.22)$ were relatively low. In this situation the practical differences between designs matched and unmatched for duration of employment are probably not very great.

\section{Smoking}

The relative risk of three to four found in this study for having ever smoked is compatible with risks found in other studies (8). Given the small number of never smokers ( 6 cases and 46 referents) the power of our data is insufficient to discriminate strongly between the multiplicative and additive models for the combined effect of smoking and coal-tar exposure; however, there was some evidence, though falling short of conventional statistical significance, for the multiplicative model. Given the uncertainty concerning the possible effects of smoking, we propose that the results that we have presented for the group as a whole, irrespective of smoking, be preferred for risk prediction, the fact always being born in mind that this group, like most working populations, included relatively few men who had never smoked.

\section{Latency}

Ideally it is desirable to identify the assumptions concerning latency which fit the data best, and to use these assumptions in formulating an exposure-response model. Unfortunately we have found that the data from this study (and we suspect from occupational epidemiologic studies generally) cannot discriminate between substantially different assumptions concerning latency. For example the difference in LR statistics between models based on all cumulative exposure and those based on the 10 years prior to diagnosis being ignored was only 3.0 (25.3 versus 22.3) for BSM, and 1.7 (29.1 versus 27.4) for $\mathrm{BaP}$, neither suggesting any improvement more than could be accounted for by chance. More formal comparisons of different latency models yielded similarly inconclusive results. We suggest that the results following from the 10-year minimum latency assumption be preferred on a priori grounds, since environmental carcinogens generally, and occupational bladder carcinogens more particularly (8), are usually assumed to require some such minimum latency period. Estimated relative risk increments $b$ from the minimum latency models are not importantly different from those based on total cumulative exposure, however.

\section{Form of exposure-response relationship}

The form of an exposure-response relationship (eg, linear, threshold, quadratic, exponential) may in theory either be chosen on a priori grounds or inferred from the data. However, as with latency, it was impossible to discriminate between importantly different models from our data. An exponential (logistic) model $[R=\exp (b x)]$ gave a likelihood ratio statistic which was marginally higher than that from the linear model for BSM, and marginally lower for BaP. The models based on grouped exposure data were all compatible with the linear model, although patterns of risk apparent from the grouped data, which are highly dependent on choice of group boundaries, may visually suggest nonlinear relationships. Our preference for the linear model is based on its compatibility with the data and its greater biological plausibility. Differences between forms of exposure-response relationships are the most important when risks from exposures much lower or much higher than those experienced in this study population are being predicted.

\section{Predicting risks}

We have mentioned many uncertainties and limitations in the models which we have estimated from our data, 
suggesting caution in predicting risks from them. However, partial ignorance is no excuse for avoiding the important practical question of what risk follows from what exposure. In the preceding discussion we argued that, for prediction, the linear model assuming a 10 -year minimum latency be preferred. Relative risks, estimated from this model, resulting from a worklife of 40 years of exposure to coal-tar volatiles are shown in table 7 for a range of concentrations of BSM and BaP exposure. Note that the confidence intervals reflect only sampling variability, and not the additional uncertainties that have been discussed. In particular, the predictions of risk from low concentrations (say, the lowest two given in the table) are heavily dependent on the linearity assumption.

We have commented that we were particularly cautious in predicting risk from BSM exposure. An alternative to using the model for BSM directly in predicting risk for a BSM concentration in a given environment is to estimate an average proportion of $\mathrm{BaP}$ in BSM in that environment and use the BaP model.

An aluminum smelter worker exposed to coal-tar volatiles at the current American Conference of Governmental Industrial Hygienists' threshold limit value (TLV) for BSM of $0.2 \mathrm{mg} / \mathrm{m}^{3}$ for 40 years is predicted from the BSM model to be about two and a half times as likely to contract bladder cancer as an unexposed person. There is currently no TLV for BaP. In Sweden an exposure limit of $5 \mu \mathrm{g} / \mathrm{m}^{3}$ has been in effect for BaP since 1982. Aluminum smelter workers exposed to this concentration for 40 years are predicted to be about five times as likely to contract bladder cancer as an unexposed person.

Finally, we must emphasize that, in the context of the discussed uncertainties in predicting risk, it is highly desirable to consider results from more than one study. We hope that comparable results from other studies will soon become available.

\section{Acknowledgments}

This research was carried out while two of us (BG Armstrong and D Cyr) were supported by the Institut de recherche en santé et sécurité du travail du Québec.

The cooperation and financial support of Alcan Smelters and Chemicals Ltd (AS\&C) and its employees is gratefully acknowledged. In particular our thanks are due to Mr J Côté and Mr M Guy, for their work in estimating exposures, and to Dr J Kelly and Mr B MacEachen, for their guidance and general support.
Table 7. Relative risks predicted following 40 years of exposure to tar volatiles. (BSM $=$ benzene-soluble matter, $\mathrm{BaP}=$ benzo-a-pyrene, $95 \% \mathrm{Cl}=95 \%$ confidence interval)

\begin{tabular}{ccc}
\hline \multicolumn{3}{c}{ BSM } \\
\hline $\begin{array}{c}\text { Concen- } \\
\text { tration } \\
\left(\mathrm{mg} / \mathrm{m}^{3}\right)\end{array}$ & $\begin{array}{c}\text { Rela- } \\
\text { tive } \\
\text { risk }\end{array}$ & $95 \% \mathrm{Cl}$ \\
\hline 1.0 & 8.1 & $3.8-17.4$ \\
0.5 & 4.5 & $2.40-9.2$ \\
0.2 & 2.42 & $1.56-4.3$ \\
0.1 & 1.71 & $1.28-2.64$ \\
0.05 & 1.35 & $1.14-1.82$ \\
0.02 & 1.14 & $1.06-1.33$ \\
0.01 & 1.07 & $1.03-1.16$ \\
\hline
\end{tabular}

\begin{tabular}{ccc}
\hline \multicolumn{3}{c}{ BaP } \\
\hline $\begin{array}{c}\text { Concen- } \\
\text { tration } \\
\left(\mu \mathrm{g} / \mathrm{m}^{3}\right)\end{array}$ & $\begin{array}{c}\text { Rela- } \\
\text { tive } \\
\text { risk }\end{array}$ & $95 \% \mathrm{Cl}$ \\
\hline 10 & 10.2 & $4.6-21.8$ \\
5 & 5.6 & $2.8-11.4$ \\
2 & 2.84 & $1.72-5.2$ \\
1 & 1.92 & $1.36-2.15$ \\
0.5 & 1.46 & $1.18-2.04$ \\
0.2 & 1.18 & $1.07-1.42$ \\
0.1 & 1.09 & $1.04-1.21$ \\
\hline
\end{tabular}

\section{References}

1. Armstrong B, Oakes D. Effects of approximation in exposure assessments on estimates of exposure-response relationships. Scand J Work Environ Health 8 (1982): suppl 1, 20-23.

2. Bjorseth A, Bjorseth $\mathrm{O}$, Fjeldstad E. Polycyclic aromatic hydrocarbons in the work atmosphere. Scand $\mathbf{J}$ Work Environ Health 4 (1978) 212-223.

3. Doll $R$. Risks of cancer in the primary aluminium industry. In: PAH-symposium Oslo 1984. Aluminium industriens Miljosekretariat, 1984.

4. Gibbs GW. Mortality of aluminum reduction plant workers, 1950 through 1957. J Occup Med 27 (1985) $761-770$.

5. International Agency for Research on Cancer. Chemical and industrial processes associated with cancer in humans. Lyon 1979. (Monographs on the evaluation of the carcinogenic risk of chemicals to humans, supplement 1).

6. International Agency for Research on Cancer. Polynuclear aromatic compounds: Part 1. Chemical, environmental and experimental data. Lyon 1983. (Monographs on the evaluation of the carcinogenic risk of chemicals to humans, volume 32 ).

7. Lindstedt G, Sollenberg J. Polycyclic aromatic hydrocarbons in the occupational environment. Scand J Work Environ Health 8 (1982) 1-19.

8. Matanoski GM, Elliot EA. Bladder cancer epidemiology. Epidemiol Rev 3 (1981) 203-229.

9. Thériault G, DeGuire L, Cordier S. Reducing aluminium: An occupation possibly associated with bladder cancer. J Assoc Med Can 124 (1980) 419-425.

10. Thériault $G$, Tremblay $C$, Cordier S, Gingras S. Bladder cancer in the aluminium industry. Lancet (1984) $947-950$.

11. Thomas DC. General relative risk models for survival time and matched case-control analysis. Biometrics 37 (1981) 673-686.

12. Walker AM, Rothman KJ. Models of varying parametric form in case-referent studies. Am J Epidemiol 115 (1982) $129-137$.

Received for publication: 26 May 1986 